that this is happening in many different ways, through policy and strategy, research and at the workplace. Those taking action include scientific associations, OSH organisations, equalities organisations, health organisations, employers and trade unions. The cases range from comprehensive gender-mainstreaming projects to simple steps that organisations can take to ensure that the $\mathrm{OSH}$ of both male and female workers is covered.

\section{WORK ABILITY IN BREAST CANCER WOMEN SURVIVORS: A QUESTIONNAIRE-BASED STUDY}

${ }^{1} \mathrm{R}$ Bonfiglioli*, ${ }^{2} \mathrm{MA}$ Musti, ${ }^{2} \mathrm{~N}$ Collina, ${ }^{2} \mathrm{E}$ Stivanello, ${ }^{2} \mathrm{C}$ Giansante, ${ }^{2} \mathrm{~S}$ De Lisio, ${ }^{3} \mathrm{~S}$ Giordani, ${ }^{2} \mathrm{C}$ Morelli, ${ }^{2} \mathrm{P}$ Pandolfi. ${ }^{1}$ Department of Medical and Surgical Sciences, University of Bologna, Occupational Health Unit, Bologna, Italy; ${ }^{2}$ Department of Public Health, Bologna Local Health Authority, Bologna, Italy; ${ }^{3}$ Oncology, Department of Primary Health Care, Bologna Local Health Authority, Bologna, Italy

\subsection{6/oemed-2018-ICOHabstracts.1495}

Introduction Breast cancer is the most common cancer in women worldwide. Early breast cancer diagnosis and improvement of therapeutic procedures have reduced the impact of treatment on function and increased the proportion of possibly employed survivors. The growth in female labour participation and the extension of working life have increased the number of women with breast cancer that work or have to face the issue of returning to work. The aim of the study was to identify predictors of reduced work ability at return to work among women treated for breast cancer.

Methods A questionnaire was sent to all 18-65 years old women resident and treated for breast cancer in Bologna Local Health Authority area in the period 2010-2012 to collect data about personal characteristics, medical history, breast cancer treatment work history and return to work. A multivariate logistic regression analysis was performed to identify predictors of reduced work ability among workingwomen.

Results A total of 1578 women were invited to fill in the questionnaire. The response rate was 53,3\%. Data of 503 workingwomen returned to work at the time of the study were analysed.

Reduced work ability at return to work was reported by $43.5 \%$ women compared to the pre-diagnosis period. Reduced work ability was significantly more common in non-cohabiting than in cohabiting/married women, in labourers than in Office clerks/sales assistants and managers and more frequent after mastectomy than after breast-conserving interventions.

Adjustments of work activities, occupational physician visits, less support from employer and colleagues and discrimination were significantly more frequently reported by women with a reduced work ability.

Conclusion Perceived reduced work ability is common in women who return to work after the treatment for breast cancer. Occupational physicians and GPs should be aware of a wide asset of factors to facilitate a successful return to work.

\section{HEALTH STATUS OF ADOLESCENT GIRLS EMPLOYED IN THE TEXTILE INDUSTRY OF TAMIL NADU, INDIA}

${ }^{1} \mathrm{~B}$ Joseph, ${ }^{2} \mathrm{NA}$ Gnanaselvam. 'Professor and Head, Occupational Health Services, St. John's Medical College, Bangalore, India; ${ }^{2}$ Faculty, Community Health, St. John's Medical College, Bangalore, India

10.1136/oemed-2018-ICOHabstracts. 1496
Introduction A 'marriage assistance scheme' prevails in Tamil Nadu, India, where unmarried adolescent girls are recruited to work for specified periods of time in textile factories in return for a bulk amount of money at the end of tenure, which is used for their marriage expenses. We aimed to assess the health status of adolescent girls working in such factories.

Methods A total of 321 adolescent girls, 107 in each study group namely, current employees, past employees and the never-been employed were interviewed for the study. Standard tools used to evaluate the health and wellbeing of the adolescents.

Result Significant difference was observed among the study groups in terms of health practices such as physical activity, hours of sleep, consumption of fruits and vegetables, and access to health care. Prevalence of menstrual irregularities was more among the current employees and past employees with $38.3 \%$ and $37.4 \%$ of them affected as compared to $18.7 \%$ among the never-been employed girls [AOR 2.42 (95\% CI: 1.42 to 4.72$)]$. Among the current and the past employees, $30 \%$ reported abuse at workplace. Significant difference in conditions such as depression and behavioural problems including emotional, conduct, hyperactivity and peer-relation problems were observed between the study groups, with more number of current and past employees suffering from these issues as compared to the never-been employed adolescents [AOR 2.25 (95\% CI: 1.22 to 4.14)]. Musculoskeletal pain was also more among the current and past employees, with neck and shoulder being the common regions of the body which were affected [AOR 5.28 (95\% CI: 2.13 to 13.1)].

Discussion Current and past employees have poorer health as compared to the never-been employed adolescents. Workplace counselling could prevent mental health morbidities among the employed adolescent girls. Appropriate ergonomic measures must be undertaken at workplaces to avoid musculoskeletal disorders among current employee.

\section{OCCUPATIONAL LUNG DISEASES IN DECEASED SOUTH AFRICAN WOMEN IN MINING}

${ }^{1}$ Ntombizodwa Ndlovu*, ${ }^{2,3} \mathrm{Jim}$ Phillips, ${ }^{2}$ Ntebogeng Kgokong, ${ }^{2}$ Trudie Vorster, 1,2 Jill Murray. 'School of Public Health, University of the Witwatersrand, Johannesburg, South Africa; ${ }^{2}$ National Institute for Occupational Health, National Health Laboratory Service, Johannesburg, South Africa; ${ }^{3}$ Biomedical Technology, Faculty of Health Sciences, University of Johannesburg, Johannesburg, South Africa

\subsection{6/oemed-2018-ICOHabstracts. 1497}

Introduction Women have worked in South African mines for over a century. During the twentieth century, employment of women underground was legally prohibited. In the asbestos mining industry, women worked in surface processing activities e.g. hand-cobbing of asbestos. Most women were undocumented in mine employment records and were thereby excluded from medical surveillance and compensation. Women continue to be exposed to asbestos in the environment. The 2004 Mining Charter permitted women to work underground and set targets to their employment across the mining industry. From 2005, the National Institute for Occupational Health (NIOH) has recorded the sex of deceased individuals examined for the detection of OLDs for statutory compensation. We compared OLDs in deceased women and men.

Methods Records were extracted from the PATHAUT autopsy database (2005-2015). The NIOH also performs autopsies for 